\title{
Nasal response in patients with diisocyanate asthma*
}

Joaquín Sastre', Anna Poltronieri', Ignacio Mahillo-Fernandez², Erika Aguado', Manuela García del Potro', Mar Fernández-Nieto'

'Allergy Dept., Fundación Jiménez Díaz and CIBER de Enfermedades Respiratorias (CIBERES) Madrid, Spain

(Institute Carlos III, Ministry of Economy and Competitiveness)

2Epidemiology Dept., Fundación Jiménez Díaz, Madrid, Spain
Rhinology 52: 431-436, 2015

DOI:10.4193/Rhino14.005

*Received for publication:

January 10, 2014

Accepted: June 4, 2014

\section{Abstract \\ Background: To date, no studies have assessed nasal and bronchial response to diisocyanates during specific inhalation chal- lenges (SIC).}

Objectives: This study was performed to assess nasal response during SIC with diisocyanates (nasal and oral breathing) in patients with suspected occupational asthma due to these agents.

Methods: Fourteen patients with suspected clinical history of diisocyanate-induced asthma were challenged with diisocynates in a $7 \mathrm{~m}^{3}$ chamber. Nasal response testing during challenges was assessed by acoustic rhinometry, peak nasal inspiratory flow (PNIF), and visual analog scale (VAS), alongside bronchial responses.

Results: Eleven patients had a significant asthmatic response to diisocyanates. None reported clear work-related nasal symptoms. In patients with positive bronchial response to diisocyanates, nasal mean minimal cross-sectional area (MCA) decreased by $26.9 \%$, nasal volume at $5 \mathrm{~cm}$ decreased by $33.5 \%$, and PNIF decreased by $28.3 \%$, all from baseline. A positive nasal response was elicited in $45 \%, 54 \%$, and $45 \%$ of patients, respectively. A significant increase in VAS was observed in 4 patients. Three patients with negative bronchial response had a negative nasal response.

Conclusion: SIC revealed an objective nasal response in around $50 \%$ of patients with occupational asthma due to diisocyanates, in spite of the fact that none of them reported work-related nasal symptoms. The clinical significance of this finding is a poor association between nasal symptoms at work and an objective nasal response during positive SIC with diisocyanates.

Key words: occupational rhinitis, occupational asthma, diisocyanates, acoustic rhinometry, nasal cytology, peak inspiratory nasal flow

\section{Introduction}

Occupational rhinitis (OR) is a very common disease accompanying occupational asthma $(O A)^{(1)}$, as it is in rhinitis of nonoccupational origin, in which rhinitis is associated to asthma in up to $90 \%$ of the cases ${ }^{(2)}$. This association seems to be greater in patients with $\mathrm{OA}$ due to high molecular weight (HMW) agents, in which an IgE mechanism is demonstrated ${ }^{(3)}$, than it is in rhinitis associated with many low molecular weight (LMW) agents, in which an allergic, but non-lgE-mediated mechanism is sugge- sted. The intensity of nasal symptoms in OR is also clearly greater when the causative agent is of HMW, and these symptoms are usually followed by OA development ${ }^{(1,3,4)}$.

As in OA, the causal role of occupational agents in OR can be documented by performing a nasal provocation test (NPT) ${ }^{(3)}$. Some studies ${ }^{(5,6)}$ have documented the use of NPT in the study of $O R$ and have shown positive responses with an increase in nasal symptoms, a reduction of nasal patency by several objective methods, an increase in volume of nasal secretions, and/or nasal 
inflammation markers. Littorin et al. ${ }^{(7)}$ demonstrated that nasal lavage fluid from subjects exposed to isocyanates presented an increase in markers of nasal inflammation; the presence of these markers was greater in patients complaining of work-related nasal symptoms with these agents. Similarly, Johnson et al. ${ }^{(8)}$ have developed an animal model to study rhinitis induced by diisocyanates. In this model, they showed that TDI inhalation induces immune-mediated allergic rhinitis resembling that which has been observed in humans.

Only 2 studies have been published on the prevalence of workrelated nasal symptoms in workers exposed to diisocyanates $(9,10)$. In these studies, the prevalence varied from 36 to $42 \%$ of workers. However, to our knowledge, no studies have specifically assessed nasal symptoms and objective measurements of nasal function during challenge tests with diisocyanates.

This study was performed to assess nasal response during challenges with diisocyanates in patients with suspected occupational asthma due to these agents.

\section{Materials and methods}

This study included 14 patients with a suspected clinical history of diisocyanate-induced asthma (12 men, 2 women; age range, 33-69 years). We included consecutive patients referred to our allergy department for this type of assessment. Seven patients were atopic. Table 1 contains the characteristics of the patients included. Ethical approval for the study was obtained from the hospital medical ethics committee and all subjects provided written informed consent to participate.

\section{Bronchial challenges}

All asthma medications, antihistamines, and nasal steroids were withheld for at least 2 weeks before the start of the specific inhalation challenge (SIC) with diisocyanates.

Methacholine challenge was performed as described elsewhere (11). This test was performed on the day before the challenge; in case of doubtful diisocyanate challenge results, the test was performed again 24 hours after the challenge. Airway responsiveness to methacholine was expressed as the cumulative provocative dose causing a 20\% fall in FEV1 (in milligrams of methacholine).

Fraction of exhaled nitric oxide (FeNO) measurements (NIOX MINO, Aerocrine, Sweden) were carried out at baseline (day before SIC) and $24 \mathrm{hr}$ after SIC ${ }^{(12)}$.

SIC with diisocyanates (TDI (toluene diisocyanate), MDI (methlylene diisocyanate), and HDI (hexamethylene diisocyanate), depending on occupational exposure, were carried out in single-blind fashion in a $7 \mathrm{~m}^{3}$ dynamic chamber as previously described ${ }^{(10)}$. During the challenge, the patients remained seated and breathed though their nose and mouth. In brief, a TDI atmosphere was generated in the chamber by passing dry air through TDI contained in a flask. The atmosphere was then injected into an ultrafiltered air stream in the chamber using the Venturi effect (5 patients). HDI (8 patients) and MDI were nebulized directly into the chamber (1 patient). Isocyanate concentration was continuously measured with an MDA monitor (model 7100; MDA Scientific; Greenview, IL, USA). The protocol has been described previously ${ }^{(10)}$. FEV1 was measured before exposure, every 10 min during the first hour after SIC, hourly until bedtime, upon awakening, and again the day after. A fall in FEV1 of $\geq 20 \%$ from baseline was regarded as a positive asthmatic response. The pattern of asthmatic responses was characterized as immediate, late, dual (immediate followed by a late response), and atypical.

\section{Nasal assessments}

Before starting at baseline and before SIC, the patients waited for 30 minutes to allow the nasal mucosa to acclimate to the local conditions.

Nasal response was monitored using a 100-mm visual analog scale (VAS) to measure nasal congestion, sneezing, and runny nose. Acoustic rhinometry (SRE 2100; RhinoMetrics, Assens, Denmark) and peak nasal inspiratory flow (Clement Clark International, Harlow, UK ) (PNIF) measurements were obtained at the same time intervals as spirometry for the first 6 hours and 24 hours after the challenge.

Using acoustic rhinometry, minimal cross-sectional area (MCA) was measured at the head of the inferior turbinate, and volume at $5 \mathrm{~cm}$ (Vol5) was also recorded ${ }^{(13,14)}$. Average values from the left and right nostril and measured in duplicate were used for analysis. A decrease in MCA, Vol 5, or PNIF of $\geq 30 \%$ from baseline and an increase in any VAS parameters of more than $2 \mathrm{~cm}$ were considered a positive response. Normal values were taken from published references ${ }^{(15,16)}$.

Nasal cytology was obtained at baseline and 24 hours after SIC. A scraping from the inferior turbinate in both nostrils was obtained using a plastic curette under direct visual inspection. The samples obtained were extended on a glass cover and stained. Grading of nasal cytograms was performed according to the procedure published by Meltzer et al. ${ }^{(17)}$.

\section{Data analysis}

The subjects' characteristics were described using either mean and standard deviation or median and quartiles for quantitative variables, and frequency distribution for qualitative variables. All variables that were not normally distributed (KolmogorovSmirnov test) were log transformed. Percent changes from baseline were summarized by geometric mean and its $95 \%$ confidence interval. The statistical significance of changes was tested by the paired Student's t test. Comparisons between different objective techniques (MCA, VOL5, PNIF) were performed by a paired Student's t test. The significance level was set at 0.05 . 


\section{Results}

Eleven patients had a significant asthmatic response to diisocyanate SIC; in 4 the response was immediate, in 2 dual, and 5 experienced late reactions. None of the patients reported clear work-related nasal symptoms. Twenty-four hours after SIC, 4 of the 11 patients had an increase in FeNo levels of greater than 30\% (patients 3, 5, 9, and 11). In 3 patients with negative bronchial challenge, there was no significant variation in methacholine PC20 or FeNO values 24 hours after SIC. Ten patients reported persistent rhinitis, 1 had a nasal polypectomy, but none of them reported clear work-related nasal symptoms. At baseline, 2 patients had abnormally low values of MCA, while 4 had abnormally low Vol 5, and 3 had abnormally low PINF. All of these patients had positive bronchial response to diisocyanates. In patients with positive bronchial response to diisocyanates, mean MCA decreased from baseline by $26.9 \%(95 \% \mathrm{Cl}-37,-15)$ $\mathrm{p}=0.0009)$, by $33.5 \%(95 \% \mathrm{Cl}-49,-12)(\mathrm{p}=0.0078)$ in Vol 5 and by $28.3 \%(95 \% \mathrm{Cl}-38,-15)(\mathrm{p}=0.0003)$ in PNIF. In these patients, MCA values revealed a decrease of $\geq 30 \%$ in $45 \%$ of them. This degree of decrease was seen in $54 \%$ of patients in Vol 5 and in $45 \%$ for PNIF values. In 3 of the patients with no bronchial response to diisocyanates, the mean MCA decrease from baseline values was $13 \%(95 \% \mathrm{Cl}-24,-6), 7.7 \%(95 \% \mathrm{Cl}-12,-4)$ in Vol 5 and $17 \%(95 \% \mathrm{Cl} 6,-30)$ for PINF values.

A positive nasal response considering a decrease $\geq 30 \%$ in Vol5 was immediate in 3 patients, while in 3 it was considered to be late. In these patients, the timing of maximal nasal response coincided with maximal FEV1 response in only 1 patient in whom immmediate response was observed (patient 7) (Figure 1).

VAS scale varied by more than $2 \mathrm{cms}$ in only 4 of the patients with positive SIC (all in congestion scale). Three of these patients exhibited nasal symptoms (immediate or late) that coincided with maximal fall in acoustic rhinometry. In the remaining patients with positive or negative SIC, no variation in VAS was observed.

In 3 patients, nasal cytology revealed eosinophils (all +) at baseline; 2 of these patients were atopic. In these 3 patients a similar number of eosinophils was observed $24 \mathrm{~h}$ after SIC in spite of positive bronchial challenge. Eosinophlis appeared after a positive SIC in only 2 patients (++). A summary of the results is shown in Table 1.

\section{Discussion}

The results of this study in subjects referred for investigation of possible OA due to diisocyanates showed that the group of patients with positive bronchial response had a statistically significant objective nasal response during challenge. A positive nasal response (decrease of $\geq 30 \%$ in MCA or Vol 5 or PNIF values) was elicited in $45 \%, 54 \%$, and $45 \%$ of patients. On the other hand, no positive nasal responses were obtained in patients having ne-

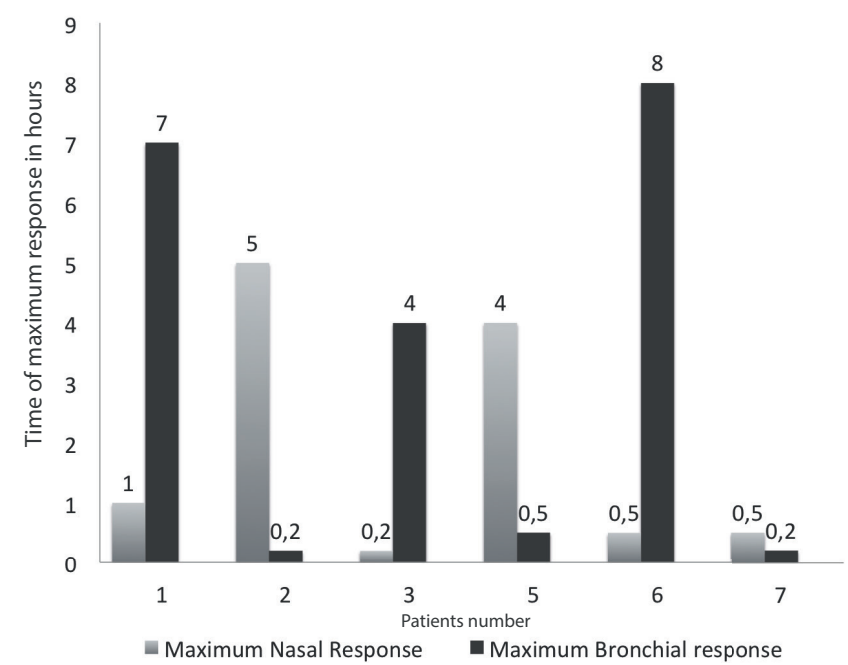

Figure 1. Timing of maximum nasal response (nasal Vol 5) and bronchial response ( FEV1) in patients with positive nasal response (decrease from baseline $\geq 30 \%$ in nasal Vol 5).

gative bronchial response, although higher fluctuation in PNIF, but not in MCA or Vol 5, was observed in 1 patient with negative SIC. This fact does not invalidate the results obtained in other patients as concerns the specificity of the results. Four patients had a variation of more than $2 \mathrm{~cm}$ on the VAS scale. A correlation with objective rhinometric measurements was found in 3 of these patients. It was not possible to find clinical characteristics (age, sex, atopy, baseline nasal or pulmonary function tests) to differentiate nasal responders vs non-responders to diisocyanates, likely due to the low number of patients included.

To date, no studies have specifically assessed nasal and bronchial response to diisocyanates. To our knowledge, there is only one study with which we may partially compare our results ${ }^{(6)}$. In the study, the authors describe nasal response during challenge by acoustic rhinometry in patients with suspected occupational asthma due to HMW and LMW agents. In the study, however, only 8 patients were challenged with diisocyanates, and all but one had negative bronchial challenges. Nevertheless, a positive nasal response was obtained in a total of 3 patients challenged with diisocyanates, but only one of them produced a positive bronchial response. Though the study used the same rhinometric criteria as in our, the different results between the two can be explained by a difference in the number of positive bronchial responses to diisocyanates. In any case, a limitation or weakness of our study is the low number of patients included and the fact that our study does not include the nasal response during a sham exposure. Therefore, further investigations are needed in this field. Nevertheless, we can conclude that a nasal response is also frequent during challenge with LMW agents, though to a lesser extent than with HMW agents.

Of note, none of our patients reported a clear history of work- 


\begin{tabular}{|c|c|c|c|c|c|c|c|c|c|c|c|c|c|c|}
\hline Patient \# & Age & Sex & Atopy & $\begin{array}{c}\text { Persistent } \\
\text { rhinitis }\end{array}$ & $\begin{array}{c}\text { Nasal } \\
\text { symp- } \\
\text { toms } \\
\text { at } \\
\text { work }\end{array}$ & $\begin{array}{c}\text { Eosino- } \\
\text { phils in } \\
\text { nasal } \\
\text { cytol- } \\
\text { ogy at } \\
\text { base- } \\
\text { line }\end{array}$ & $\begin{array}{c}\text { Baseline } \\
\text { MCA } \\
\left(\mathrm{cm}^{2}\right)\end{array}$ & $\begin{array}{c}\text { Baseline } \\
\text { Vol } 5 \\
\left(\mathrm{~cm}^{3}\right)\end{array}$ & $\begin{array}{l}\text { Baseline } \\
\text { PNIF } \\
\text { L/sec }\end{array}$ & $\begin{array}{c}\text { Maxi- } \\
\text { mum } \\
\text { Postch- } \\
\text { allenge } \\
\% \text { de- } \\
\text { crease } \\
\text { in MCA } \\
\text { from } \\
\text { base- } \\
\text { line }\end{array}$ & $\begin{array}{c}\text { Maxi- } \\
\text { mum } \\
\text { Postch- } \\
\text { allenge } \\
\% \text { de- } \\
\text { crease } \\
\text { in Vol } \\
5 \text { from } \\
\text { base- } \\
\text { line }\end{array}$ & $\begin{array}{c}\text { Maxi- } \\
\text { mum } \\
\text { Postch- } \\
\text { allenge } \\
\% \text { de- } \\
\text { crease } \\
\text { in PINF } \\
\text { from } \\
\text { base- } \\
\text { line }\end{array}$ & $\begin{array}{c}\text { Eosino- } \\
\text { phils in } \\
\text { nasal } \\
\text { cytolo- } \\
\text { gy after } \\
\text { chal- } \\
\text { lenge }\end{array}$ & $\begin{array}{c}\text { Bron- } \\
\text { chial } \\
\text { re- } \\
\text { sponse } \\
\text { of SIC } \\
\text { (di- } \\
\text { isocy- } \\
\text { anate }\end{array}$ \\
\hline 1 & 37 & $\mathrm{~F}$ & NO & YES & NO & NO & 0.535 & 6.120 & 90 & -25.23 & -30.07 & -11.11 & NO & $+(\mathrm{HDI})$ \\
\hline 2 & 54 & M & NO & YES & NO & NO & 0.575 & 7.305 & 100 & -38.26 & -43.53 & -30.00 & NO & $+(\mathrm{HDI})$ \\
\hline 3 & 28 & M & NO & NO & NO & NO & 0.650 & 6.615 & 160 & -33.85 & -42.18 & -12.50 & NO & $+(\mathrm{HDI})$ \\
\hline 4 & 52 & $M$ & YES & YES & NO & NO & 0.865 & 7.080 & 200 & -24.28 & -24.51 & -45.00 & NO & $+(\mathrm{TDI})$ \\
\hline 5 & 62 & $M$ & YES & YES & NO & YES(+) & 0.635 & 9.000 & 60 & -48.03 & -41.11 & -33.33 & YES(+) & $+(\mathrm{TDI})$ \\
\hline 6 & 33 & $M$ & YES & $\begin{array}{c}\text { YES/nasal } \\
\text { polypec- } \\
\text { tomy }\end{array}$ & NO & YES(+) & 0.865 & 19.845 & 40 & -45.66 & -77.05 & -25.00 & YES(+) & $+(\mathrm{HDI})$ \\
\hline 7 & 61 & $M$ & NO & NO & NO & YES(+) & 0.605 & 9.350 & 90 & -30.00 & -30.00 & 40.00 & YES(+) & $+(\mathrm{TDI})$ \\
\hline 8 & 38 & $\mathrm{~F}$ & YES & YES & NO & NO & 0.415 & 1.560 & 80 & 1.20 & -9.94 & -25.00 & NO & $+(\mathrm{HDI})$ \\
\hline 9 & 33 & $M$ & YES & YES & NO & NO & 0.360 & 2.290 & 110 & -8.33 & 6.77 & -36.36 & NO & $+(\mathrm{MDI})$ \\
\hline 10 & 39 & M & YES & YES & NO & NO & 0.675 & 2.020 & 160 & -23.70 & -16.34 & -25.00 & YES(++) & $+(\mathrm{HDI})$ \\
\hline 11 & 44 & $M$ & NO & NO & NO & NO & 0.725 & 2.355 & 120 & -0.69 & -13.59 & -16.67 & YES(++) & $+(\mathrm{HDI})$ \\
\hline Mean (SD) & & & & & & & $0.62 \pm 0.1$ & $6.68 \pm 5.2$ & $110 \pm 47.3$ & $-26.9 \% *$ & $-33.5 \% *$ & $-28.3 \% *$ & & \\
\hline 12 & 56 & $M$ & YES & YES & NO & NO & 0.675 & 7.69 & 90 & -5.93 & -6.76 & -22.22 & NO & - (TDI) \\
\hline 13 & 33 & $M$ & NO & YES & NO & NO & 0.645 & 2.56 & 100 & -7.75 & -11.89 & -25.00 & NO & - (HDI) \\
\hline 14 & 69 & $\mathrm{~F}$ & NO & NO & NO & NO & 0,855 & 7.69 & 66 & -23.98 & -4.22 & 6.06 & NO & - (TDI) \\
\hline Mean (SD) & & & & & & & $0.72 \pm 0.1$ & $5.98 \pm 2.9$ & $85.3 \pm 17$ & $-16 \%$ & $-6 \%$ & $-17.7 \%$ & & \\
\hline
\end{tabular}

${ }^{*}=p<0.005$ from baseline values. Numbers in italics: individual abnormal values. SD: standard deviation. SIC: specific inhalation challenge with diisocyanates. TDI (toluene diisocyanate), MDI (methlylene diisocyanate), HDI (hexamethylene diisocyanate).

related rhinitis symptoms while working, which contrasts with 2 previous studies of nasal symptoms in patients exposed to diisocyanates, which described a prevalence that varied from 36 to $42 \%$ of workers ${ }^{(9,10)}$. The explanation for this discrepancy may be the inherent subjectivity of nasal symptoms, the greater importance given to bronchial symptoms in comparison with nasal ones, or a failure to discriminate nasal symptoms at work, since most patients complained of persistent rhinitis. In fact, previous studies have described the lack of correlation between nasal symptoms and objective nasal techniques in the general population ${ }^{(18)}$ or even during occupational nasal challenges
(19). Another interesting finding is the timing of maximal nasal response by objective methods and maximal FEV1 response (immediate or late), irrespective of the positive cut-off for positivity. Occurrence at the same time was found in only 1 patient with positive nasal and bronchial response, (immediate response). We have no clear explanation for this finding, but in the study of Castano et al. ${ }^{(6)}$, which analyzes nasal and bronchial response to occupational agents, a significant concomitant decline in nasal patency and bronchial caliber was also found in only 13 out of $43 \mathrm{SIC}$ tests. Concerning nasal inflammation, which was assessed by nasal cytology at baseline and 24 hours after challenge, eosi- 
nophils were detected in 3 at baseline; 2 of these patients were atopic. However, a similar number of eosinophils was observed $24 \mathrm{~h}$ after SIC in spite of positive bronchial challenge in these patients, but in other 2 patients, eosinophlis appeared only after a positive SIC. Of note, these patients had no nasal response as measured by objective techniques. It is possible that due the timing of nasal cytology after challenge ( 24 hours), we may have missed the window for an early eosinophil recruitment in the nasal mucosa in patients with nasal response, or there may be nasal inflammation but without a significant decrease in nasal patency parameters. An increase of nasal inflammatory markers, including eosinophils, has been described in patients with rhinitis and asthma due to LMW agents ${ }^{(20,21)}$.

When analyzing the results of objective techniques used to measure nasal patency, acoustic rhinometry, and PNIF, no significant difference was found among the different outcomes (MCA vs Vol 5; MCA vs PNIF; or Vol 5 vs NPIF) in patients with positive or negative bronchial response to diisocyanates. Nevertheless, when analyzing results patient by patient, there are some incongruencies. Only 3 patients had a decrease of values of $\geq 30 \%$ from baseline in the 3 outcomes, namely, MCA, Vol 5, and PNIF. The Vol 5 outcome seems to have higher sensitivity, since all the patients with a significant decrease in this parameter also had a significant decrease in the others, except in 2 patients in whom PINF was considered positive but MCA and Vol 5 did not reach clinical positivity. However, due to the higher variability of PNIF values ${ }^{(16)}$, acoustic rhimometric outcomes-especially Vol 5-should be recommended to measure nasal obstruction during challenges ${ }^{(6)}$. VAS also had lower sensitivity. This can be explained by the poor correlation between acoustic rhinometry and subjective nasal patency ${ }^{(18,19)}$.

In summary, SIC produced an objective nasal response in around $50 \%$ of patients with occupational asthma due to diisocyanates despite the fact that none of them reported work-related nasal symptoms. The clinical significance of this finding is a poor association between nasal symptoms at work and an objective nasal response during positive SIC with diisocyanates. This can be explained by the predominance of bronchial symptoms or a failure to discriminate symptoms at work due to the persistence of nasal symptoms.

Further investigations of rhinitis associated with diisocyanate sensitization are needed to characterize its prevalence, pathogenic mechanisms, or timing of response when it presents alone or in association with asthma.

\section{Acknowlegdement}

This study was supported by in part by CIBERES (CIBER de Enfermedades Respiratorias). Thanks to Oliver Shaw for editorial assistance.

\section{Authorship contribution}

All contributors have participated in the design, generation and/ or interpretation of results and in the different revisions before the submission of the manuscript. All co-authors gave the final approval of the version to be published.

\section{Conflicts of Interest}

Mar Fernández-Nieto, Anna Poltronieri, Ignacio Mahillo, Erika Aguado, and Manuela García del Potro have no conflicts to disclose.

Joaquín Sastre reports having served as a consultant to Thermofisher, Schering-Plough, Sanofi, Novartis, Faes Farma, Genentech, Roche, and GSK; having been paid lecture fees by Novartis, GSK, Stallergenes, UCB, Thermofisher; as well as having received grant support from Thermofisher, GSK, and ALK-Abello. These conflicts of interests do not affect this research.

\section{References}

1. Malo JL, Lemiere C, Desjardins A, Cartier A. Prevalence and intensity of rhinoconjunctivitis in subjects with occupational asthma. Eur Respir J. 1997; 10: 1513-1515

2. Compalati E, Ridolo E, Passalacqua G, Braido F, Villa E, Canonica GW. The link between allergic rhinitis and asthma: the united airways disease. Expert Rev Clin Immunol. 2010; 6: 413-423.

3. Moscato G, Vandenplas O, Gerth Van Wijk $R$, et al. EAACI Task Force on Occupational Rhinitis. Allergy. 2008; 63: 969-980

4. Cortona G, Pisati G, Dellabianca A, Moscato G. Respiratory occupational allergies: the experience of the Hospital Operative Unit of Occupational Medicine in Lombardy from 1990 to 1998. G Ital Med Lav Ergon. 2001; 23: 64-70.
5. Airaksinen $L$, Tuomi $T$, Vanhanen $M$, Voutilainen R, Toskala E. Use of nasal provocation test in the diagnostics of occupational rhinitis. Rhinology. 2007; 45: 40-46.

6. Castano R, Gautrin D, Thériault G, Trudeau C, Ghezzo H, Malo JL. Occupational rhinitis in workers investigated for occupational asthma. Thorax. 2009; 64: 50-54.

7. Littorin M, Welinder $H$, Skarping G, Dalene $M$, Skerfving S. Exposure and nasal inflammation in workers heating polyurethane. Int. Arch. Occup. Environ. Health. 2002; 75: 468-474.

8. Johnson VJ, Yucesoy B, Reynolds JS, et al. Inhalation of toluene diisocyanate vapor induces allergic rhinitis in mice. J Immunol. 2007;179:1864-71

9. Bernstein DI, Korbee L, Stauder T, Bernstein JA, Scinto J, Herd ZL, Bernstein IL. The low prevalence of occupationaasthma and antibody-dependent sensitization to diphenylmethane diisocyanate in a plant engineered for minimal exposure to diisocyanates. J Allergy Clin Immunol. 1993; 92: 387-396.

10. Ucgun I, Ozdemir N, Metintaş M, Metintaş S, Erginel S, Kolsuz M. Prevalence of occupational asthma among automobile and furniture painters in the center of Eskisehir (Turkey): the effects of atopy and smoking habits on occupational asthma. Allergy. 1998; 53: 1096-100.

11. Sastre J, Fernández-Nieto M, Novalbos A, De Las Heras M, Cuesta J, Quirce S. Need for monitoring nonspecific bronchial hyperresponsiveness before and after isocyanate inhalation challenge. Chest, 2003; 123: 1276-1279. 
12. Sastre J, Costa C, García del Potro M, Aguado E, Mahillo I, Fernández-Nieto M. Changes in exhaled nitric oxide after inhalation challenge with occupational agents. J Invest Allergol Clin Immunol. 2013; 23: 421-427.

13. Sastre J, Lluch-Bernal M, Bustillo AM, et al. Allergenicity and cross-reactivity of Russian olive pollen (Eleagnus angustifolia). Allergy. 2004; 59: 1181-1186.

14. Ganslmayer M, Spertini F, Rahm F, Terrien $\mathrm{MH}$, Mosimann B, Leimgruber A. Evaluation of acoustic rhinometry in a nasal provocation test with allergen. Allergy. 1999; 54 974-979.

15. Millqvist E, Bende M. Reference values for acoustic rhinometry in subjects without nasal symptoms. Am J Rhinol. 1998; 12: 341 343.

16. Ottaviano G, Scadding GK, Coles S, Lund VJ Peak nasal inspiratory flow; normal range in adult population. Rhinology. 2006; 44 32-35.

17. Meltzer EO, Jalowayski AA. Nasal cytology in clinical practice. Am J Rhinol. 1988; 2: 47-54.

18. Yepes-Nuñez JJ, Bartra J, Muñoz-Cano R, et al. Assessment of nasal obstruction: Correlation between subjective and objective techniques. Allergol Immunopathol (Madr). 2013; 41: 397-401

19. Castano R, Trudeau C, Ghezzo H. Correlation between acoustic rhinometry and subjective nasal patency during nasal challenge test in subjects with suspected occupational rhinitis; a prospective controlled study. Clin Otolaryngol. 2010; 35: 462-467.

20. Palczynski C, Walusiak J, Ruta U, et al. Occupational asthma and rhinitis due to glutaraldehyde: changes in nasal lavage fluid after specific inhalatory challenge test. Allergy. 2001; 56: 1186-1191.

21. Palczynski C, Walusiak J, Krakowiak A, et al.
Nasal lavage fluid examination in diagnostics of occupational allergy to chloramine. Int J Occup Med Environ Health. 2003; 16: 231-240.

Joaquín Sastre, MD, PhD, FAAAAI

Allergy Deptartment

Fundación Jiménez Díaz

Av. Reyes Católicos 2

28040 Madrid

Spain

Tel.: +34-91-5498225

Fax: +34-91-5499498

E-mail: jsastre@fjd.es

\title{
ADVERTISEMENT
}

\section{ERS-FELLOWSHIPS 2015}

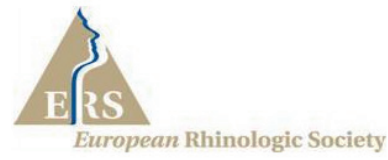

Sponsored by

\section{THE EUROPEAN RHINOLOGIC SOCIETY}

\author{
Available to ERS-members
}

One place available on each of the following Courses in 2015

12th International Course in advanced Sinus Surgery

Amsterdam, The Netherlands, March 26-27, 2015

Course Director: Prof. Dr. W.J. Fokkens

Fax: +31 205669573

Email: m.b.vanhuiden@amc.uva.nl

51st International Workshop on Functional and Endoscopic Sinus Techniques with Advanced Seminar

Graz, Austria, July 8-11, 2015

Course Director: Prof. Dr. H. Stammberger

Email: claire.zwerina@meduni-graz.a

\section{$\mathbf{2 2}^{\text {th }}$ Rhinoplasty Course (International Course in Modern}

Rhinoplasty Techniques)

Amsterdam, The Netherlands, October 28-30, 2015

Course Director: Peter W Hellings, MD, PhD

Email: m.b.vanhuiden@amc.uva.nl $16^{\text {th }}$ International Course on Reconstructive and Aesthetic Surgery of the Nose and Face "Around the Nose" Nijmegen, The Netherlands, June 10-12, 2015

Course Director: Dr. K. Ingels

Email: y.savelkoul-broekman@pao.umen.nl

Endoscopic approach to Rhinosinusitis in Sinonasal Disease London, United Kingdom, October 14-17, 2015 ,

Course Directors: Prof. V.J. Lund

Fax: +4402078379279

Email: sarah.harris@ucl.ac.uk

Information; ricky.kemp@ucl.ac.uk

Sponsorship comprises a sum of 1200 Euro to assist in both registration fees and costs of accommodation/travelling. More information and application forms are available on the website:

http://www.europeanrhinologicsociety.org

Applications should be submitted before January $15^{\text {th }}, 2015$. For questions you can contact: Judith Kosman, Secretary ERS, rhinologysecretary@amc.nl

Applicants should be under the age of 40 years without former granting of an ERS-fellowship. 